\title{
JUEZ TERCERO E IMPARCIAL COMO ELEMENTO "PREMISA" DEL PROCESO JUSTO ENTRE CONSTITUCIÓN Y FUENTES SUPRANACIONALES
}

Email: dinacciraffaele@yahoo.com

\begin{abstract}
RESUMEN: La uniformidad del cuadro normativo europeo y constitucional, requiriendo un juez tercero e imparcial, impone nuevas perspectivas exegéticas, y ello no sólo por la eficacia de las disposiciones procedentes de fuentes superiores, sino porque los requisitos que caracterizan a la jurisdicción representan, por deseo constitucional, el elemento "premisa" del proceso justo. De aquí la exigencia de que los caracteres de la jurisdicción estén tutelados, incluso en esas situaciones que quedan fuera de las previsiones normativas. Y, desde esta perspectiva, se hace necesario recuperar el valor de garantía de las sanciones procesales, "arrinconadas" por una jurisprudencia no siempre en línea con la objetividad del dato normativo.
\end{abstract}

\begin{abstract}
The consistency of the Europeanand constitutional framework, requiring a third and impartial judge, calls for a new critical interpretation; partially because of the effectiveness of wordings coming from higher law, but also because the jurisdictional requirements constitute, according to the constitutional will, the precondition for a fair trial. Hence the need to protect the above mentioned issues, even in those cases that aren't normatively provided for. And in this perspective, the value of procedural safe- guards needs again to be stressed, by overruling a case -law not always complying with written law.
\end{abstract}


SUMARIO: I. De las fuentes convencionales a las comunitarias: hacia el reforzamiento del derecho a un juez equitativo. - II. La "construcción" subyacente de la reforma constitucional del "proceso justo". - III. El valor de la autonomía de contenido de la tercialidad e imparcialidad. - IV. Hacia una nueva perspectiva exegética: la obligación de tutela de la neutralidad incluso en situaciones no contempladas. - V. La insuficiencia de instrumentos de tutela preventiva y el "auxilio" de las sanciones procesales. - VI. El vicio de capacidad. - VII. La inutilizabilidad. - VIII. La inexistencia. - IX. Conclusiones.

\section{I.- DE LAS FUENTES CONVENCIONALES A LAS COMUNITARIAS: HACIA EL REFUERZO DEL DERECHO A UN JUEZ EQUITATIVO}

La idea de proceso como momento antagonista de composición del pleito supone que el mismo lo decida un órgano tercero e imparcial. Las fuentes internacionales ya habían acogido dicha realidad ${ }^{1}$ con una uniformidad que permite afirmar que las características indicadas, que determinan la función jurisdiccional, constituyen una norma de derecho internacional generalmente reconocida ${ }^{2}$. La evolución normativa se dirige

\footnotetext{
${ }^{1}$ El art. 10 de la Declaración universal de los derechos humanos, ya desde 1948, prevé que "Everyone is entitled in a full equality to a fair and public hearing by an independent and impartial tribunal, in the determination of his rights and obligations and of any criminal charge against him"; el art. 14.1 del Pacto internacional de los derechos civiles y políticos [1966] establece, por su parte, que "in the determination of any criminal charge against him, or of his rights and obligations in a suit at law, everyone shall be entitled to a fair and public hearing by a competent, independent and impartial tribunal established by law"; fórmula totalmente análoga se se encuentra en el art. 6.1 de la Convenio europeo para la protección de los derechos humanos y de las libertades fundamentales [1950], que prevé que "in the determination of his rights and obligations or of any criminal charge against him, everyone is entitled to a fair and public hearing within a reasonable time by an independent and impartial tribunal established by law". Para un conjunto de apuntes sobre los horizontes supranacionales en particular, en relación con los perfiles que enfoca la Constitución, vid., por todos, CHIAVARIO, Processo e garanzie della persona, vol. II, Le garanzie fondamentali, Milano, 1984, 43; sobre este tema, vid. UBERTIS, Principi di procedura penale europea. Le regole del giusto processo, Milano, 2000, 23; GIUNCHEDI, Cultura dell' "equo processo" europeo e giustizia interna, en Dal principio del giusto processo alla celebrazione di un processo giusto, coordinadores Cerquetti-Fiorio, Padova, 2002, 77.

${ }^{2}$ Para la exclusión de las normas de derecho internacional reconocidas generalmente por las "normas internacionales pactadas", véanse Corte constitucional, n 238 de 2014, nº 129 de 2008, nº 288 de 1997, $\mathrm{n}^{\circ} 323$ de 1989. Sin embargo, se ha sostenido que las normas pactadas podrían incluirse entre las «normas de derecho internacional reconocidas generalmente » que el ordenamiento jurídico italiano debe adoptar en aplicación del art. 10, párrafo 1, de la Constitución. En particular, se ha especificado que la llamada a los derechos fundamentales del individuo que contiene el art. 2 de la Constitución constituye una cláusula general de reenvío que se refiere no sólo a los diferentes derechos de la persona proclamados constitucionalmente, sino también a todos aquellos intereses que «expresados por la evolución de la ciencia social encuentran su consagración en actos o convenciones internacionales»

(BRICOLA, Prospettive e limiti alla tutela penale della riservatezza, en Riv. it. dir. proc. pen., 1967, 1098; VASSALLI, Libertà di stampa e tutela penale dell'onore, en questa Rivista, 1967, I, 24). El planteamiento, aunque con un objetivo encomiable, no parece que pueda compartirse. El mismo choca con la naturaleza de ley ordinaria de los actos legislativos mediante los cuales los preceptos del Convenio de Roma y del Pacto de Nueva York han encontrado acceso al ordenamiento interno italiano (CHIAVARIO, La convenzione europea dei diritti dell'uomo nel sistema delle fonti normative in materia penale, Milano, 1969, 41). Surgen otras perplejidades en relación con el pretendido valor constitucional de las normas pactadas del considerar que una conclusión diferente llevaría al peligro de modificaciones constitucionales esquivando el específico instrumento de revisión contemplado en el art. 138 de la Constitucional. (Corte constitucional $n^{\circ} 15$ de 1996; $n^{\circ} 315$ de 1990; $n^{\circ} 323$ de 1989, $n^{\circ} 188$ de 1980).
} 
hacia un reforzamiento de la figura de las fuentes internacionales para garantizar los requisitos de la jurisdicción reconociéndose, con el art. 47 de la Carta de los derechos fundamentales de la Unión Europea ${ }^{3}$, el derecho al examen del asunto por parte de un juez «independiente e imparcial, establecido previamente por ley». En particular, además de la puntualización del conjunto de garantías del juez a través de la llamada a la «preconstitución» ${ }^{4}$, con el art. 52 se prevé que «eventuales limitaciones del ejercicio de los derechos y libertades reconocidos por la presente Carta deben estar previstos por la ley y respetar el contenido esencial de dichos derechos y libertades». Así pues, se introduce la inatacabilidad de un "núcleo duro" que resiste a las posibles derogaciones normativas, las cuales, por otro lado, se establece que pueden aportarse sólo si son «necesarias» y si «responden efectivamente a finalidades de interés general reconocidas por la Unión o por exigencias de protección de los derechos y libertades ajenos». De esta manera se dibuja un cuadro normativo que blinda las características mínimas de la jurisdicción ${ }^{5}$

Por otro lado, no debe olvidarse que la Carta de los derechos fundamentales de la Unión europea ha sido proclamada en Niza el 7 de diciembre de 2000 y, después de revisarla, aprobada de nuevo en Estrasburgo el 12 de diciembre 2007 por el Parlamento Europeo junto con el Consejo y las Comisión, con el objeto de adaptarla a los contenidos del Tratado de Lisboa.

Así pues, estamos en presencia de un recorrido genético dirigido hacia una osmosis de contenidos entre la Carta y los Tratados básicos de la Unión Europea. Asimismo, es necesario destacar que el art. 6 del TUE reconoce entre las fuentes primarias del derecho unitario europeo la Carta de Niza y los principios que la misma contiene ${ }^{6}$.

Esta circunstancia lleva a obvias consecuencias en términos de incidencia de la fuente supranacional en el derecho interno, perfilándose poderes de desaplicación, por parte del juez italiano, de todas aquellas normas que no logran tutelar los "requisitos mínimos" de la jurisdicción.

Sobre el tema véanse también los argumentos de CAPRIOLI, Colloqui riservati e prova penale, Torino, $2000,37$.

${ }^{3}$ La Carta es de 12 de diciembre de 2007, publicada en el DOUE el 14 de diciembre de 2007, serie C, y ha retomado, con algunas adaptaciones, la Carta de Niza de 7 de diciembre de 2000, sustituyéndola a partir de la entrada en vigor del Tratado de Lisboa.

${ }^{4}$ Totalmente ausente en las anteriores normas pactadas y convencionales.

${ }^{5}$ Sobre este tema en general, vid. GIUNCHEDI, La tutela dei diritti umani nel processo penale, en Questioni nuove di procedura penale, Padova, 2007, 109.

${ }^{6}$ Por último, la llamada a un juez tercero e imparcial está enunciada en la Directiva U.E., n 343 de 2016. 
Respecto a este aspecto, la misma Corte constitucional ha reconocido el carácter vinculante de los principios compartidos tanto por la fuente interna como por la comunitaria $^{7}$. Y es más, imposibilitándose la aplicabilidad del art. 49 de la Carta de los derechos fundamentales de la U.E. sólo porque la norma interesada no es reconducible ratione materiae al derecho de la Unión Europea, de hecho se le reconoce a la fuente normativa en cuestión una eficacia equivalente a la de los Tratados sobre la Unión Europea $^{8}$, con obvias consecuencias en terma de poderes de desaplicación por parte del juez interno de las disposiciones normativas que no están en línea con la obligación europea.

\section{II.- LA “CONSTRUCCIÓN" SUBYACENTE A LA REFORMA CONSTITUCIONAL DEL "PROCESO JUSTO”}

Sin embargo, el tema de la propagación interna del precepto jurídico supranacional podría perder relevancia si se tiene en cuenta la transposición, en la Carta de los valores, de las garantías de tercialidad e imparcialidad conjugadas con la introducción de la regulación del proceso justo 9 . Este aspecto puede compartirse en la medida en que se tenga conciencia de la naturaleza preceptiva de la fuente constitucional, que no puede deducirse a una mera enunciación programática de valores $^{10}$. Y más aún si se considera que la reforma del art. 111 de la Constitución ha demostrado, respecto a las fuentes europeas, en concreto en referencia a los temas de la jurisdicción, una mayor conciencia operativa. No es casual que el incipit del art. 111 de la Constitución italiana afirme que «la jurisdicción se aplica mediante el proceso justo regulado por la ley», desvelan una relación "instrumental esencial” entre jurisdicción y proceso justo $^{11}$.

\footnotetext{
${ }^{7}$ Vid. Corte constitucional $n^{\circ} 28$ de 2010.

${ }^{8}$ Vid. Corte constitucional $n^{\circ} 210$ de 2013.

9 Para una panorámica de la jerarquía de las fuentes supranacionales, vid, si se desea, DINACCI, Interpretazione "europeisticamente" orientata tra fonti normative e resistenze giurisprudenziali, in I principi europei del processo penale, coordinador Gaito, Roma, 2016, 57.

${ }^{10}$ Sobre este tema, remite a las consideraciones de CELOTTO, La Costituzione: Carta dei valori o norma precettiva?, in Processo penale e Costituzione, coordinador Dinacci, Milano, 2010, 1 sig.

${ }^{11}$ Sobre este punto véanse los argumentos de DEAN, I principi costituzionali di terzietà ed imparzialità del giudice nella sistematica del processo penale, en Dal principio del giusto processo alla celebrazione di un processo giusto, coordinadores Cerquetti y Fiorio, Padova, 2002, 3. Pero en esa ocasión se afirma que el art. 111 de la Constitución demarca una relación de identidad entre jurisdicción y proceso justo. La afirmación puede compartirse en la medida en que se parta del principio que no pueden existir uno sin la otra.
} 
Éste último hace posible la operatividad de la primera poniendo de manifiesto sus requisitos mínimos ${ }^{12}$. A su vez, el párrafo 2 de la misma disposición específica que «cada proceso se desarrolla en el contradictorio entre las partes, en condiciones de igualdad, ante un juez tercero e imparcial. La ley asegura su duración razonable». De esta manera quedan establecidos los requisitos mínimos e indefectibles del proceso justo. En consecuencia, puede afirmarse que con el "supuesto constitucional" "13 la intención era la de dar respuesta concreta a los inconvenientes operativos derivados de la dificultad de establecer un parámetro de referencia para la definición del proceso justo. No es casual que la jurisprudencia de la Corte Constitucional definiera la alocución de que se trata con esa fórmula «en la que se compendian los principios que la Constitución dicta en relación tanto con los caracteres de la jurisdicción, como con los derechos de acción y defensa en el juicio» ${ }^{14}$. Con la introducción de una específica previsión que fija los requisitos mínimos de existencia del supuesto, el proceso justo se convierte en una regla «inderogable para el ejercicio de la función judicial y, al mismo tiempo, núcleo estructural de la jurisdicción» ${ }^{15}$.

Desde esta perspectiva, la estrecha relación entre el dictum según el cual la «jurisdicción se aplica mediante el proceso justo» y aquél sobre la base del cual «cada proceso se desarrolla ante un juez tercero e imparcial» exalta las características mínimas de la jurisdicción que también constituyen, a causa de la indicada relación de “instrumentalidad necesaria", las características mínimas de existencia de un proceso justo.

Dicha realidad asigna la jurisdicción el papel del elemento presupuesto del proceso justo ${ }^{16}$.

Por otro lado, más allá del indiscutible contenido del art. 111 de la Constitución, la afirmación queda confirmada por la simple consideración de que el juez es preexistente al proceso y, por tanto, a su celebración; de ello es demostración el hecho de que, por deseo constitucional, el juez mismo debe ser no sólo natural sino también preconstituido.

\footnotetext{
${ }^{12}$ Vid. DEAN, I princìi costituzionali di terzietà ed imparzialità, cit., 3; sobre los perfiles estáticos y dinámicos de la jurisdicción vid. PISANI, Giurisdizione penale, en Enc. dir, XIX, Milano, 1970, 383; DALIA - PIERRO, Giurisdizione penale, en Enc. giur., XV, Roma, 1989, 1.

${ }^{13}$ Sobre el concepto de supuesto vid. CONSO, I fatti giuridici processuali penali, rist., Milano, 1982, 15.

${ }^{14}$ Corte Constitucional n ${ }^{\circ} 131$ de 1996.

${ }^{15}$ Así DEAN, I principi costituzionali di terzietà ed imparzialità, cit., 4. Sobre este punto, permítanme citar a DINACCI, Giurisdizionale penale e giusto processo verso nuovi equilibri, Padova, 2002, 6.

${ }^{16}$ Sobre este tema vid., si se desea, DINACCI, Giurisdizionale penale e giusto processo verso nuovi equilibri, cit., 32.
} 


\section{III.- EL VALOR DE LA AUTONOMÍA DE CONTENIDO DE LA TERCIALIDAD E IMPARCIALIDAD}

La clave de lectura que acabamos de indicar de la reforma constitucional del art. 111 de la Constitución pone en evidencia el intento, por un lado, decodificar expresamente los caracteres de la tercialidad e imparcialidad del juez y, por otro lado, de especificar el papel presupuesto de la jurisdicción respecto al proceso.

No es casual que para alcanzar dicho último objetivo se haga necesaria una delimitación más específica de los requisitos de existencia de la jurisdicción. No cabe duda de que los adjetivos calificativos de tercialidad e imparcialidad se refieren a una función que "naturalmente" los incluye ${ }^{17}$, pero la falta de una codificación expresa exponía el «aparato deontológico del juez» a una tutela débil, obligando al intérprete a obtener los principios de tercialidad e imparcialidad como afirmaciones derivadas y consecuentes de otro principio constitucional ${ }^{18}$. Pero de esta manera, se llegaba a una "construcción" del principio débil desde el punto de vista de los contenidos por ser incapaz de asumir una capacidad operativa propia autónoma, y "atado" por los límites o la evanescencia de esos principios de los que se pretendía que descendiera. Así, mientras, por un lado, se saldaba el reconocimiento del principio de imparcialidad al art. 3 de la Constitución ${ }^{19}$, por otro lado, siguiendo la línea de la idea según la cual la imparcialidad debía entenderse como «independencia de los intereses presentes en el juicio», se invocaba el art. 108, párrafo 2 de la Constitución, reduciendo de hecho la imparcialidad a una de las posibles formas de independencia del juez ${ }^{20}$.

Sobre esta línea también se ha colocado la afirmación de la Corte Constitucional según la cual «en los órganos de jurisdicción especial también deben garantizarse tanto

\footnotetext{
${ }^{17}$ En este sentido, parece emblemático lo que destaca GIARDA, Imparzialità del giudice e difficoltà operative derivanti dall'incompatibilità, en Il giusto processo, Actas del Congreso de Salerno, Milano, 1998, 35, que subraya «la opinión confirmada por testimonios que se encuentran en las actas de la Asamblea Constituyente, para la que la imparcialidad de los jueces debe enumerarse entre aquellos principios no escritos que preexisten incluso al ejercicio del poder constituyente», y que «forman una especie de plataforma de derecho natural o, si se desea, de aquellos derechos inviolables del hombre, a los que se refiere, con el necesario énfasis incluso léxico, el art. 2 de la Constitución, otorgándoles valor y dignidad constitucional». Sobre los caracteres de alteridad del "tercero" respecto a las partes vid., ex plurimis, en clave teórica-general, las observaciones de SPAGNA MUSSO, Giudice (nozione e principi costituzionali), en Enc. dir., XVIII, Milano, 1969, 932.

${ }^{18}$ A este respecto permítane citar a DINACCI, Giurisdizionale penale e giusto processo verso nuovi equilibri, cit., 8 .

${ }^{19}$ Corte Constitucional, $\mathrm{n}^{\circ} 128$ de 1974.

${ }^{20}$ Corte Constitucional, ${ }^{\circ} 93$ de 1965.
} 
el derecho a la defensa como la independencia y la imparcialidad del juez; independencia e imparcialidad que, incluso antes de ser escritas en disposiciones específicas de la Constitución, con el art. 108, reposan en el conjunto de las normas constitucionales relativas a la Magistratura y al derecho a la defensa» ${ }^{21}$.

De esta manera, en la jurisprudencia de la Consulta se establece un principio que vive de forma extendida ${ }^{22}$.

De ello es prueba la afirmación según la cual la referencia contenida en el art. 108 de la Constitución a la independencia y no a la imparcialidad se explica y se justifica «por el hecho de que, garantizando la función jurisdiccional, la Constitución, por ello mismo, ha garantizado la imparcialidad del juez» ${ }^{23}$.

Pero así, resulta evidente, la imparcialidad no quedaba reconocida como valor autónomo y se diluía en el principio del que se la hacía descender.

Quizás conscientes de ello, se ha tendido a distinguir las áreas conceptuales de la independencia y de la imparcialidad, devolviendo a ésta última una dignidad autónoma. En efecto, se ha afirmado que «el principio de independencia se dirige a garantizar la imparcialidad del juez o, mejor dicho, como se ha observado, la exclusión de cualquier peligro de parcialidad asegurando al juez una posición totalmente super partes». Por lo tanto es necesario excluir por lo que se refiere al juez «cualquier interés, incluso indirecto, en el asunto por decidir y debe exigirse que la ley garantice la ausencia de cualquier expectativa de ventajas, como temores de algún perjuicio restableciendo los instrumentos adecuados para tutelar la objetividad de la decisión» ${ }^{24}$. Aquí, diferencia de las demás orientaciones, la independencia asume una posición "al servicio", como instrumento de realización de la imparcialidad. Por lo tanto esta última constituye el valor- finalidad tutelado por el ordenamiento ${ }^{25}$.

\footnotetext{
${ }^{21}$ Corte Constitucional, $\mathrm{n}^{\circ} 92$ de 1962.

22 Sobre este punto vid. los argumentos de DI CHIARA, L'incompatibilità endoprocessuale del giudice, Torino, 2000, 14.

${ }^{23}$ Así SCOCA, Indipendenza del giudice tributario e giurisprudenza costituzionale, en Giur. cost., 1964, 1075. Además de las clásicas páginas de CALAMANDREI, Processo e democrazia, in Opere giuridiche, I, Napoli, 1965, 651, sobre este tema, vid., también, con especial vigor, ANDRIOLI, Le giurisdizioni speciali nella Repubblica, en Le giurisdizioni speciali amministrative, Milano, 1956, 13.

${ }^{24}$ Corte Constitucional, $\mathrm{n}^{\circ} 60$ de 1969

25 Sobre este punto vid. DI CHIARA, L'incompatibilità endoprocessuale del giudice, cit., 16, donde se especifica que «a través de la tutela de imparcialidad de cada juez se tutela la imparcialidad de la
} 
Pero eso no quita que tercialidad e imparcialidad no constituyan una endíadis; por el contrario, son portadoras de una específica autonomía de contenido ${ }^{26}$.

En efecto, la tercialidad se relaciona con una posición institucional del juez, diferente y equidistante de las partes, mientras que la imparcialidad caracteriza al juez en su dimensión operativa ${ }^{27}$.

Así pues, las características de la jurisdicción, tal y como las establece el art. 111 de la Constitución, también recubren perfiles ordinamentales que inciden en la "posición" del juez respecto al caso que se le somete capaces de influir en su imparcialidad $^{28}$. No debe perderse de vista que esta última puede violarse incluso con una correcta abstracta aplicación de las reglas procesales y ordinamentales; y por este motivo el mismo principio de establecimiento previo del juez podría entrar en conflicto de forma abstracta con el de imparcialidad ${ }^{29}$.

\section{IV.- HACIA UNA NUEVA PERSPECTIVA EXEGÉTICA: LA OBLIGACIÓN DE LA NEUTRALIDAD DEL JUEZ INCLUSO EN SITUACIONES NO CONTEMPLADAS}

Las consideraciones que hemos desarrollado vuelven rendir cuenta de la elección del Constituyente de explicitar expresamente los requisitos de tercialidad e imparcialidad para dar aplicación a la enseñanza de la Corte Constitucional italiana cuando invitaba a asegurar «la exclusión de cualquier peligro de parcialidad que quedara asegurada para el 1 juez una posición totalmente super partes» ${ }^{30}$, afirmando

\footnotetext{
jurisdicción que es el resultado último de la concreta imparcialidad de cada uno de los jueces y se convierte en característica fisiológica del Estado». En este sentido vid. Corte Constitucional, $\mathrm{n}^{\circ} 131$ de 1996.

${ }^{26}$ Para un análisis del trabajo parlamentario en el que se pone de manifiesto dicha voluntad legislativa vid., si se desea, DINACCI, Giurisdizione penale e giusto processo verso nuovi equilibri, cit., 22.

2727 Vid. DEAN, I princìpi costituzionali di terzietà ed imparzialità del giudice, cit., 7 .

${ }^{28}$ Cabe pensar al tema de la separación de las carreras entre órgano solicitante y juzgador. Sobre este tema vid. SABATINI, Il pubblico ministero nel processo penale, II, Torino, 1948, 21; ILLUMINATI, La separazione delle carriere come presupposto per un riequilibrio dei poteri delle parti, in Il pubblico ministero oggi, Milano, 1994, 219 y, si se desea, DINACCI, Giurisdizione penale e giusto processo verso nuovi equilibri, cit., 144. Vid. TEDH Fey c. Austria, 24 de febrero de 1993; Id., Saint-Marie c. Francia, 16 diciembre 1992; Id., Nortier c. Netherlands, 24 de agosto de 1993; Id., Hauschildt c. Denmark, 24 de mayo de 1989.

${ }^{29}$ Sobre este punto, vid. DI CHIARA, L'incompatibilità endoprocessuale del giudice, cit., 18.

${ }^{30}$ Vid. Corte Constitucional, $\mathrm{n}^{\circ} 60$ de 1969.
} 
que, de lo contrario, «todas las demás reglas y garantías procesales perderían su concreto significado» ${ }^{31}$.

Así pues, se pone de manifiesto que el Juez de las leyes ha captado el valor presupuesto de los requisitos caracterizadores de la jurisdicción; y de esta conciencia deriva una nueva perspectiva metodológica.

Lo que hay que tutelar no es tanto la abstracta configurabilidad de los centros de tutela de las características jurisdiccionales sino su «concretarse» ${ }^{32}$ en el ordenamiento. El planteamiento parece compartido por esa jurisprudencia europea que, en tema de imparcialidad derivada del anterior ejercicio de funciones en el ámbito del procedimiento, ha aclarado que lo que pone de manifiesto es «el alcance así como la naturaleza de dichas decisiones ${ }^{33}$; especificándose que, en los supuestos en los que cualquier tipo de pronunciación implica una valoración sobre el tema de la responsabilidad del acusado, la imparcialidad puede aparecer dudosa ${ }^{34}$.

Por lo tanto, allá donde se cree, más allá de la previsión normativa, una situación jurídica o de hecho que pueda atentar contra la neutralidad del juez, el ordenamiento no puede quedar indiferente. Y dicha solución parece totalmente coherente con la voluntad de legislador constitucional de introducir una tutela expresa de las figuras de tercialidad e imparcialidad del juez. En definitiva, incluso en el caso concreto de que no forme parte de las hipótesis legislativas capaces de tutelar tercialidad e imparcialidad, la situación no puede y no debe resultar indiferente para el ordenamiento. Y ello no sólo a la luz de la obligación de conformidad constitucional, sino también por la obligación perceptiva derivada de esa fuente comunitaria que impone un juez tercero e imparcial. Estos últimos, por otro lado, son aspectos funcionales que a menudo se salen de los marcos normativos.

\footnotetext{
${ }^{31}$ Vid. Corte Constitucional, $\mathrm{n}^{\circ} 306$ de 1997; sobre este tema vid. también Corte Constitucional, $\mathrm{n}^{\circ} 241$ de 1999 donde se especifica que la tercialidad es «una forma de ser de la jurisdicción»; Corte Constitucional, $n^{\circ} 155$ de 1996 donde se afirma que los requisitos constitucionales de los jugadores «aún antes de ser una pretensión de la parte constituyen exigencias objetivas e irrenunciables del ordenamiento».

${ }^{32}$ Para dicha perspectiva metodológica, conscientes de que «un análisis dirigido a la reconstrucción [de una] figura jurídica debe iniciar de su concreta aplicación» se permita el reenvío a DINACCI, Il giudizio di rinvio nel processo penale, Padova, 2002, 3.

${ }^{33}$ Vid. TEDH, Fey c. Austria, 24 de febrero de 1993; Id., Saint-Marie c. Francia, 16 de diciembre de 1992; Id., Nortier c. Netherlands, 24 de agosto de 1993.

${ }^{34}$ Vid. TEDH, Hauschildt c. Denmark, 24 de mayo de 1989.
} 


\section{V.- LA INSUFICIENCIA DE INSTRUMENTOS DE TUTELA PREVENTIVA Y EL “AUXILIO” DE LAS SANCIONES PROCESALES}

La observación anterior induce no sólo a volver a meditar sobre todos los aquellos institutos dirigidos a garantizar tercialidad e imparcialidad del juez, sino también a valorar el significado de las sanciones procesales dirigidas a salvaguardar los rasgos mínimos de la jurisdicción. En definitiva, ante un cuadro constitucional y comunitario modificado, el intérprete no puede hacer «como si no hubiera pasado nada » y debe «alinear las opciones exegéticas a con la tutela impuesta por los enunciados normativos prevalentes» ${ }^{35}$. Por lo demás, el instinto de conservación que a menudo caracteriza a la jurisprudencia cada vez que se discute de sanciones procesales está enraizada en esa contraposición entre eficiencia y garantía que ya no tiene motivo de existir. Tras la introducción de la revisión procesal ${ }^{36}$, dichas actitudes interpretativas en tema de sanciones procesales corren el peligro de anular exactamente el resultado que se desea salvaguardar. La conclusión está aún más destinada a valer si se aplica al tema de los requisitos mínimos de la función jurisdiccional. Aquí se controvierte sobre una "condición" del proceso justo cuya falta de tutela conlleva su correspondiente violación que si se comprueba ante el TEDH, genera una situación jurídica que lleva a anular el resultado procesal a través del caso de revisión totalmente nuevo.

El tema adquiere significado central puesto que las figuras jurídicas específicamente destinadas a la tutela de la tercialidad e imparcialidad de la función jurisdiccional no resultan en consonancia con la finalidad, ya sea desde el punto de vista de la regulación abstracta, como por lo que respecta a su actuación concreta.

La conclusión se refiere a las figuras jurídicas para la incompatibilidad, la abstención y la recusación, identificadas por la Corte Constitucional misma como momento cualificado de garantía del proceso justo ${ }^{37}$.

\footnotetext{
35 Sobre este tema vid. TARUFFO, L'interpretazione della legge, Milano, 1980, 323.

36 Vid. Corte Constitucional, $\mathrm{n}^{\circ} 113$ de 2011, que ha declarado la ilegitimidad constitucional del art. 630 del código procesal penal italiano en la parte en la que no prevé un caso de revisión diferente de la sentencia o del auto penal de condena con la finalidad de permitir la reapertura del proceso si se hiciera necesario en aplicación del art. 46.1, del Convenio para la protección de los derechos humanos y de las libertades fundamentales para conformarse con una sentencia de la Tribunal europeo de derechos humanos.

${ }^{37}$ Vid. Corte Constitucional, $n^{\circ}$ 306, 307 y 308 de 1997. Desde un punto de vista más amplio de la tutela de los caracteres de la jurisdicción, aunque conscientes de la peculiaridad operativa de la figura jurídica, habría que considerar también la remisión del proceso.
} 
En particular, en esa instancia se ha afirmado que si el prejuicio de la tercialidad del juez procede de las funciones ejercidas dentro de un mismo procedimiento penal, dicho prejuicio es previsible. En estos supuestos se ha reconocido, además de la tutela de restablecimiento que queda en manos de la iniciativa del juez y de las partes a través de los instrumentos de la abstención y de la recusación, la exigibilidad de la tutela preventiva que debe aplicarse con medios organizativos capaces de garantizar un «desarrollo espontáneo del proceso justo». En efecto, se ha especificado que, cuando la fuerza de prejuicio deriva no de una sentencia sino de una decisión adoptada en un procedimiento diferente, el instrumento de tutela no puede identificarse en posteriores pronunciación es añadidas sobre el art. 34 del código procesal penal italiano, sino que ha de buscarse en el área de los institutos de la abstención y de la recusación, dirigidos éstos también a tutelar la salvaguardia de la tercialidad del juez ${ }^{38}$. De esta manera se delinea un ámbito de actuación de los esquemas de la abstención-recusación por un lado y de la incompatibilidad por otro diferentes. Sin embargo, dicha diferenciación fronteriza no encuentra tanto su origen en una diversidad de presupuestos operativos de las figuras jurídicas, sino en la diferente opción de evitar innumerables sentencias añadidas sobre el art. 34 del código procesal penal ${ }^{39}$. En efecto, la Corte Constitucional misma, después de haber identificado los institutos de la incompatibilidad, de la abstención y de la recusación como los instrumentos procesales más adecuados para tutelar el principio de imparcialidad, reconoce que «dichos casos [están] sometidos a regulación sustancialmente unitaria y [están] sujetos por la matriz común de condiciones que impiden el ejercicio de específicas funciones jurisdiccionales» ${ }^{40}$. Y sobre la base de dicha conciencia se explica la exigencia de establecer un "límite operativo" entre el la figura de la incompatibilidad y las de la abstención y la recusación, observando que sería «imposible pretender del legislador un esfuerzo de abstracción y tipificación que logre identificar a priori todas las situaciones en las que el juez, habiendo ejercido funciones judiciales en un procedimiento diferente, podría encontrarse después en una situación de incompatibilidad en el procedimiento penal siguiente» ${ }^{41}$. En particular, si se le impusiera dicho peso al legislador «todo el tema de

\footnotetext{
${ }^{38}$ Vid. Corte Constitucional, $\mathrm{n}^{\circ} 331$ de 1997. En los mismos términos vid. Id., $\mathrm{n}^{\circ} 86$ de 2013 y n 247 de 2010.

${ }^{39}$ En estos términos, Corte Constitucional, n 307 de 1997.

40 Así, Corte Constitucional, $\mathrm{n}^{\circ} 308$ de 1997.

${ }^{41}$ Vid., una vez más, Corte Constitucional, n 308 de 1997.
} 
las incompatibilidades, dispersadas en una casuística sin fin, se convertiría en refractaria de cualquier intento de administración mediante acto de organización preventiva» ${ }^{42}$.

Así pues, se pone de manifiesto la reconstrucción de un sistema que se propone establecer la necesaria tutela del principio del proceso justo en todos los casos en los que pueda resultar comprometida la imparcialidad del juez. No es casual que se haya reconocido que las «razones del prejuicio» son «objetivamente idénticas ya sea cuando el juez ha manifestado su convicción dentro del mismo procedimiento mediante un acto o el ejercicio de una función a la que legislador atribuye abstracta y preventivamente efectos de prejuicio, ya sea cuando la valoración sobre el fondo del asunto se ha expresado en un procedimiento diferente (o bien en el mismo procedimiento, pero mediante un acto que no supone dicha valoración) y los efectos de prejuicio deben, pues, comprobarse en concreto gracias a las figuras jurídicas de la abstención y de la recusación» ${ }^{43}$. La identidad afirmada de las razones del prejuicio encuentra confirmación desde el punto de vista normativo de la coincidencia, o mejor dicho, en la relación de continente a contenido de los casos de incompatibilidad en los de abstención y recusación. Esta circunstancia caracteriza a éstas últimas como formas de tutela cualificada de la imparcialidad del juez. Viéndolo bien, incompatibilidad, abstención y recusación constituyen una forma de progresión referente no tanto al ámbito del límite de tutela sino a los modos de aplicación de la misma. Resulta innegable que sólo con la recusación se le ofrece a la parte un instrumento procesal dirigido a hacer valer y reconocer la existencia de una causa de incompatibilidad y de algunas causas de abstención ${ }^{44}$.

En este contexto, la recusación juega un papel de "garantía final" para la tutela de la imparcialidad del juzgador. Y entonces resulta obvio que, en un análisis dirigido a establecer así como a medir el grado de resistencia de los mecanismos de control del respeto de los caracteres constitucionales de la jurisdicción, hay que tomar como punto de referencia la figura jurídica de la recusación. Pero ésta última resulta caracterizada por un campo de operatividad más limitado respecto a los casos contemplados para la declaración de abstención; en efecto, mientras que para éstas últimas también asumen

\footnotetext{
${ }^{42}$ Vid. Corte Constitucional, $\mathrm{n}^{\circ} 307$ de 1997.

${ }^{43}$ Vid. Corte Constitucional, $\mathrm{n}^{\circ} 383$ de 2000.

${ }^{44}$ Sobre este punto hay que observar que mientras existe absoluta identidad de casos con las previsiones de la incompatibilidad, no se da la misma situación respecto los casos de abstención y recusación incluso después de la sentencia de la Corte Constitucional, $n^{\circ} 283$ de 2000.
} 
valor las «graves razones de conveniencia», no sucede lo mismo por lo que respecta a la figura jurídica de la recusación. Éste aspecto asume más valor a la luz de esa decisión de la Corte Constitucional que, ampliando el marco de tutela de la imparcialidad del juez ha aclarado que la «formulación del art. 36 letra h) ley del código procesal penal tiene una esfera de aplicación suficientemente amplia para incluir también las hipótesis en las que el prejuicio deriva de funciones ejercidas en un procedimiento diferente» ${ }^{45}$.

A dicha decisión ha seguido la que ha declarado la legitimidad constitucional del art. 37 del código procesal penal «en la parte en la que no prevé que las partes puedan recusar al juez que, llamado decidir sobre las responsabilidades de un imputado, haya expresado en otro procedimiento, incluso no penal, una valoración de mérito sobre el mismo hecho en relación con el mismo sujeto». Resulta al momento evidente que, a pesar de las intervenciones de la Corte en el tejido del art. 37 del código procesal penal, los casos de recusación siguen siendo más limitados respecto a los que legitiman una petición de abstención. En efecto, la Consulta italiana, adoptando una declaración de ilegitimidad, ha evitado realizar una equiparación entre las dos regulaciones teniendo en cuenta las graves razones de conveniencia. Dicha decisión resulta incomprensible en la medida en que la misma Corte que ha considerado el art. 37 del código procesal penal el lugar más apropiado para «colmar, mediante una declaración de cierre, la falta del principio del proceso justo denunciada» ${ }^{46}$. Éste parece ser un supuesto en el que al intento prestablecido no ha seguido el resultado deseado.

Sin embargo, tras una atenta lectura de la decisión, se pone de manifiesto una precisa voluntad de no equiparar, con una valoración en abstracto, los casos de abstención a los de recusación. En efecto, siguiendo la línea de la jurisprudencia constitucional $^{47}$, se ha afirmado expresamente que «si el prejuicio por la imparcialidad

\footnotetext{
${ }^{45}$ Vid. Corte Constitucional, $\mathrm{n}^{\circ} 113$ de 2000. Sobre el tema afrontado por la Corte vid. DANIELE, L'imparzialità del giudice tra dovere di astensione e potere di ricusazione, en Giur. it., 1999, 1282; INZERILLO, Il difficile equilibrio tra diritto al "giusto processo" e valore dell'imparzialità del giudice penale nelle sentenze della Corte costituzionale, en Giur. cost., 1998, 1263; PICA, Ricusazione ed astensione, en Dig. disc. pen., XII; Torino, 1997, 227; RIVELLO, Sui rapporti tra l'incompatibilità e l'astensione o la ricusazione di un giudice, en Giur. cost., 1997, 3357.

${ }^{46}$ Vid. Corte Constitucional, $\mathrm{n}^{\circ} 283$ de 2000. Sobre el tema en la doctrina en diferentes sentidos vid. DI CHIARA, Linee evolutive della giurisprudenza costituzionale in tema di imparzialità del giudice, en Riv. it. dir. proc. pen., 2000, 85; RIVELLO, Il principio dell'imparzialità del giudice nella giurisprudenza costituzionale e negli inter-venti del legislatore, en Cass. pen., 1999, 3030; ID., L'incompatibilità del magistrato che abbia anticipato, in una precedente sentenza, le proprie valutazioni sulla responsabilità penale del soggetto sottoposto a giudizio, ivi, 1997, 663.

${ }^{47}$ Vid. Corte Constitucional n $306, n^{\circ} 307$ y n $^{\circ} 308$ de 1997.
} 
del juez no fuera reconducible a alguno de los supuestos de abstención y recusación ya previstos por el ordenamiento, la tutela del proceso justo podría garantizarse solicitando una intervención dirigida ampliar el ámbito de aplicación de dichas figuras jurídicas» ${ }^{48}$.

Pero de esta manera el Juez de las leyes, colocándose como elemento "dispensador" de un cuadro normativo dirigido a salvaguardar la tercialidad y la imparcialidad del juez, invita recurrir una intervención suya cada vez que se presenten en concreto situaciones que atenten contra el principio del proceso justo y no sean han reconducibles a los esquemas de la abstención o la recusación. Respecto este punto no pueden esconderse perplejidades; las mismas tiene su origen del argumento contradictorio de la Corte que, por un lado, considera que debe identificar una figura de cierre para tutelar el principio del proceso justo y, por otro lado, por el contrario, pide que se le consulte cada vez que se plantee una violación de sus principios no eliminable a través de las figuras de abstención y recusación. Asimismo, de esta manera, la Consulta parece asignarse un papel que, muy lejos del papel del Juez de las leyes, va asumiendo cada vez más aspectos de naturaleza legislativa.

Aunque consientes de los problemas interpretativos relacionados con el numerus clausus de los supuestos de recusación, la Corte habría podido realizar una intervención menos sectorial, tendente a equiparar los casos de abstención y los de recusación. Todo ello no ha tenido lugar y, ante la subsistente inercia del legislador ${ }^{49}$, es necesario tomar conciencia de que la salvaguardia de la tercialidad y la imparcialidad del juez está confiada a una regulación que diferencia casos de tutela del "deber de imparcialidad", reconducible son los supuestos abstención, de los del "derecho a la imparcialidad", que se coagulan en los supuestos de recusación ${ }^{50}$. La desigualdad asume un significado más sólo si se piensa que la relación incompatibilidad, abstención y recusación se caracteriza por el establecimiento en esta última figura del momento de "garantía final". En efecto, sólo a través de la recusación la parte puede pretender que se "elimine" a aquel juez tan "deontológicamente sordo", para quedarse en el estrado incluso ante situaciones que imponen un deber de abstención. Si, conscientes de esto, se siguen considerando no

\footnotetext{
${ }^{48}$ Vid. Corte Constitucional n ${ }^{\circ} 283$ de 2000.

${ }^{49}$ Por corrección es necesario indicar que el momento de "expansión" de los poderes de la jurisprudencia de la Corte Constitucional es consecuencia de una culpable inercia del poder legislativo que tiene la función de prevenir que se multipliquen las intervenciones de la Consulta sobre un mismo tema.

${ }^{50}$ La terminología es de SATTA, Astensione e ricusazione del giudice, en Enc. dir., III, Milano, 1958, 947.
} 
equiparables los casos de abstención con los de recusación significa no querer tutelar efectivamente los caracteres constitucionales de la jurisdicción.

Entonces resulta evidente el conflicto con la enunciación según la cual «en el ámbito del principio del proceso justo del que esta Corte, en numerosas ocasiones, ha definido los perfiles sobre la base de las disposiciones constitucionales referentes al tema de la jurisdicción, ocupa un lugar central imparcialidad-neutralidad del juez, a falta de la cual todas las demás reglas y garantías procesales perderían su significado concreto» ${ }^{51}$.

Ahora bien, considerando que las figuras jurídicas de la abstención y la recusación tienen el idéntico objetivo de tutelar los caracteres constitucionales de la jurisdicción y en particular que el legislador confía la efectividad de dicha tutela a la figura de la recusación, resulta totalmente injustificada una regulación de los casos de recusación que no contenga también los de abstención.

Sale a la luz un perfil de racionalidad que podría dar sensibilidad a la Corte Constitucional en el supuesto de una nueva intervención sobre la base de esa afirmación según la cual las exigencias de tutela del proceso justo no pueden garantizarse sólo con la obligación del juez de abstenerse en el caso en el que se den «otras graves razones de conveniencia», pues dicha causa de abstención no se encuentra entre las previstas en el art. 37 del código procesal penal como motivo de recusación ${ }^{52}$.

Sin embargo, incluso queriendo pensar desde una perspectiva de iure condendo, caracterizada por una regulación que equipare los casos de abstención y recusación, se plantea una regulación incapaz de tutelar adecuadamente los caracteres constitucionales y comunitarios de la jurisdicción.

La afirmación tiene su origen en el hecho de que a través de dichas figuras jurídicas la protección de la imparcialidad del magistrado está subordinada, por un lado, a la iniciativa de las partes y, por otro, a la rigidez de los términos de presentación de la instancia de recusación establecidos so pena de vencimiento. El planteamiento del

\footnotetext{
${ }^{51}$ Corte Constitucional, ${ }^{\circ} 306$ de 1997; sobre el tema vid. también Corte Constitucional, $n^{\circ} 241$ de 1999 donde se precisa que la tercialidad es «una forma de la jurisdicción»; Corte Constitucional, $\mathrm{n}^{\circ} 155$ de 1996 cuando se afirma que los requisitos constitucionales de los juzgadores «aún antes de ser una pretensión de la parte constituyen exigencias objetivas e irrenunciables del ordenamiento». Más recientemente, vid. Corte Constitucional, ${ }^{\circ} 86$ de 2013.

${ }^{52}$ Vid. Corte Constitucional, $n^{\circ} 283$ de 2000.
} 
código choca con el de la jurisprudencia de la Corte Europea que en varias ocasiones ha puesto de manifiesto que la efectiva tercialidad e imparcialidad deben considerarse «como un canon objetivo indeclinable para la regulación de la función jurisdiccional» ${ }^{53}$. Viéndolo bien, se trata de requisitos de tutela mínimos que no puede decirse que la actual regulación de la abstención y recusación satisfagan. Efectivamente, tras la transposición expresa en la Constitución de los principios de tercialidad e imparcialidad del juez, sobre todo considerando el papel instrumental que se viene asignando a los caracteres constitucionales de la jurisdicción para la realización del proceso justo, la tutela de dichos principios no puede confiarse a una regulación que limita el ámbito de excepción a estrechísimos términos previstos so pena de vencimiento y, sobre todo, a la iniciativa de la parte interesada. En realidad, frente a la evolución de la jurisprudencia constitucional así como de la misma Constitución, es necesario constatar que la imparcialidad del juez ya no es un derecho que pueda "gestionar" el sujeto particular pudiendo también decidir no ejercerlo, sino que estamos en presencia de un "interés público" que ya no es disponible ${ }^{54}$.

Desde esta perspectiva, la regulación de la abstención y recusación muestra que es inadecuada para garantizar el respeto de los rasgos constitucionales de la jurisdicción ${ }^{55}$.

\section{VI.- EL VICIO DE CAPACIDAD}

El carácter inadecuado de los criterios de naturaleza preventiva induce a trasladar el campo de investigación a la búsqueda de tutelas póstumas de los caracteres de la jurisdicción penal. Así, la atención se concentra en las disposiciones sancionadoras que atienen a los perfiles de capacidad del juez. Y, en esta vía, no puede ignorarse el momento de incidencia de la orden constitucional y del precepto comunitario sobre la norma positiva ${ }^{56}$. En esas esferas, imponiéndose la garantía de un juez tercero e imparcial, se expresa un precepto que se presenta como elemento integrador de la norma

\footnotetext{
${ }^{53}$ Sobre este tema, vid. UBERTIS, L'incompatibilità del giudice ha pure risvolti europei, en Dir. pen. e proc., 1996, 1520; PATANE', Nuovi orientamenti sulle capacità del giudice, en Giust. pen., 1997, III, 497. En jurisprudencia, vid. Corte EDU, Hauschildt c. Denmark, 24 de mayo de 1989.

${ }^{54}$ En este sentido TREVISSON-LUPACCHINI, La ricusazione del giudice nel processo penale, cit., 264.

${ }^{55}$ En esta dirección vid., si se desea, DINACCI, Giurisdizione penale e giusto processo verso nuovi equilibri, cit., 301.

${ }^{56}$ La referencia es al art. 47 de la Carta de los derechos fundamentales de la Unión Europea.
} 
ordinaria. En dicha situación, desde la perspectiva ya indicada de una posible revisión procesal consecuencia de la evasión de normas sancionadoras que tutelan la regulación del justo proceso, no resulta comprensible la persistencia de una acción judicial dirigida a negar la reconducibilidad de la falta de tercialidad e imparcialidad del juez al mismo esquema legal del art. 178, letra a), del código procesal penal ${ }^{57}$. Las opciones operativas resultan aún menos comprensibles si se piensa en las carencias de las explicaciones utilizadas. En efecto, se ha especificado que el defecto de capacidad del juez debe entenderse como «falta de los requisitos necesarios para el ejercicio de las funciones jurisdiccionales y no también como defecto de las condiciones específicas para el ejercicio de dichas funciones en un determinado procedimiento» ${ }^{58}$.

El dictum, reiterado una y otra vez más por costumbre que por convicción, carece de apoyos normativo. El art. 178, párrafo 1, letra a) del código procesal penal, refiriéndose al vicio de capacidad del juez, no distingue entre capacidad genérica y específica. Si a dicha constatación se añade el régimen de taxatividad de los actos nulos $\mathrm{y}$, en consecuencia, la imposibilidad de proceder a lecturas "diferentes" de las objetivadas en el dato de ley, resulta fácil comprender que las conclusiones alcanzadas por la jurisprudencia no son la consecuencia de un recorrido interpretativo del dato de ley, sino una "reconstrucción" (recte, emanación) del mismo sobre la base de probables exigencias de políticas de organización de las oficinas.

Tampoco puede discutirse la conclusión alcanzada sobre la base del art. 33 párrafo 2 del código procesal penal; si es verdad que éste último lleva a cabo una función de "reglamento de límites" del vicio de capacidad, también es verdad que en dicho perímetro no cabe espacio para el supuesto de la actividad llevada a cabo por un juez incompatible y, por tanto por un juez afectado por la fuerza de la prevención y en cualquier caso carente de tercialidad e imparcialidad.

Y no es casual que la jurisprudencia constitucional misma, junto a la europea, haya considerado juez no idóneo al sujeto que se encuentre en aquellas situaciones que,

\footnotetext{
57 Vid. Casación, Sala VI, 4 de noviembre de 2015, P.O., en Mass. Uff., n 266326; Id., Sala VI, 9 de septiembre de 2015, A., ivi, n 264637; Id., Sala VI, 27 de abril de 2012, T., en Dir. e giust. on line; Id., Salas Unidas, 24 de noviembre de 1999, Scrudato, en Giust. pen., 2000, II, 398; Id., Sala III, 20 de noviembre de 1999, Sanasi, en Mass. Uff., n. 214808; Id., Sala VI, 13 de mayo de 1999, Baldini, ivi, nº 214065.

${ }^{58}$ Entre otras vid. Casación, Sala III, 5 de diciembre de 2013, C., en Mass. Uff., $\mathrm{n}^{\circ}$ 258918; Id., Sala III, 14 de noviembre de 2003, J., en Casación. penal, 2005, 1984; Id., Sala VI, 14 de enero de 2000, Petralia, en Mass. Uff., n 216403; Id., Salas Unidas, 24 de noviembre de 1999, Scrudato, cit.
} 
aunque no estén reguladas, se hallen caracterizadas por la llamada "fuerza de la prevención" que lleva a la falta de los requisitos funcionales de tercialidad e imparcialidad $^{59}$. El mensaje es claro: la falta de idoneidad del juez no puede convertirse en un hecho neutro para el ordenamiento. Éste debe encontrar en su interior instrumentos de observación de lo que ya es, por deseo constitucional, un presupuesto del proceso. Y dichos instrumentos, y ello dada la naturaleza indisponible de los valores tutelados, no puede sustraerse al mecanismo de garantía sancionadora de las invalideces procesales. Debe compartirse esta observación aún más en la medida en la que se analizan los pasos argumentativos de aquellas decisiones que tienden a excluir el vicio de capacidad en el supuesto de actuaciones procesales llevadas a cabo por un juez sospechoso. En efecto, los mismos denotan una evidente contradicción pues por un lado se excluye, con la finalidad de detectar el vicio de capacidad, la capacidad específica de ejercicio y, por otro lado, aunque sea en referencia a la incompetencia funcional ${ }^{60}$, se considera relevante «la idoneidad específica del órgano para adoptar una determinada decisión ${ }^{61}$. Y si la

\footnotetext{
${ }^{59}$ Vid. TEDH, Fay c. Austria, cit; Id., Sainte Marie c. Francia, cit.; Id., Nortier c. Olanda, cit.. V. también Corte Constitucional, $\mathrm{n}^{\circ} 241$ de $1999 ; \mathrm{n}^{\circ} 290$ de $1998, \mathrm{n}^{\circ} 31$ y 346 de $1997 ; \mathrm{n}^{\circ} 131,155$ y 371 de 1996 ; $\mathrm{n}^{\circ} 432$ del1 $1995 ; \mathrm{n}^{\circ} 453$ y 455 de 1994; $\mathrm{n}^{\circ} 439$ de $1993 ; \mathrm{n}^{\circ} 124,186$ y 399 de $1992 ; \mathrm{n}^{\circ} 401$ y 502 de 1991 ; $\mathrm{n}^{\circ} 496$ de 1990.

${ }^{60}$ Sobre este punto vid. RICCIO, La competenza funzionale nel diritto processuale penale, Torino, 1959, 62 , según el cual la competencia funcional sería aquella «competencia establecida en referencia a una situación procesal de relaciones entre órganos o de relación entre actuaciones, más analíticamente como competencia determinada en referencia a una relación de naturaleza procesal entre órganos que se identifica con una situación de dependencia, de correlación, paritaria y de coordinación de funciones o bien a una relación entre la actuación que ha de llevarse a cabo y la actuación anterior»; SABATINI, Trattato dei procedimenti incidentali nel processo penale, cit., 136; LEONE, Trattato di diritto processuale penale, I, Napoli, 1961, 371.

${ }^{61}$ En este sentido vid. Casación, Sala III, 19 de abril de 1991, Spataro, en Cass. pen., 1992, 1256, 646, donde se especifica que «la incompetencia funcional, incidiendo en la idoneidad especifica del juez, es de carácter absoluto y debe observarse incluso de oficio en cualquier estado y grado del procedimiento». En el caso de autos la Corte ha observado un vicio de incompetencia funcional en la violación de la regla según la cual el juez competente para juzgar en segunda instancia la sentencia del juez de primera instancia es el Tribunal de Apelación. A este respecto se precisa que la competencia funcional «queda establecida por el reparto de los asuntos penales entre los diferentes jueces del Estado, por la que a un juez le corresponde el poder-deber de tratar determinadas partes de un proceso mientras que las otras son de competencia de otros jueces». Vid. también Casación, Salas Unidas, 20 de julio de 1994, De Lorenzo, en Riv. pen., 1994, 847, donde se afirma que «la incompetencia funcional equivale a desconocer el reparto de atribuciones del juez en relación con el desarrollo del proceso y sus efectos tienen reflejo directamente en la idoneidad especifica del órgano para la adopción de una determinada decisión. Ésta, aunque no haya encontrado tampoco una explícita previsión en el nuevo código procesal penal, dado que está caracterizada por la construcción normativa de las asunciones del juez y el desarrollo de la relación procesal, se deduce del sistema y expresa toda su imponente relevancia en relación con la legitimidad de la decisión tomada por el juez, porque si falta, dicha decisión deja de ser conforme con los parámetros normativos de referencia». En el caso concreto la Corte, en aplicación de los principios enunciados, ha reconocido como afectada por incompetencia funcional y en consecuencia viciada de nulidad absoluta la decisión de aplicación de una medida cautelar adoptada por un Juez de Investigaciones Previas en el caso en el que, tratándose de delitos ministeriales, existía una especial competencia funcional del colegio prevista por el art. 7 de la Ley Constitucional 16 de enero y 1989, $\mathrm{n}^{\circ} 1$.
} 
incompetencia funcional se pone en relación con la idoneidad específica, puede observarse cada vez que se detecta un vicio de capacidad específica de ejercicio ${ }^{62}$. Pero todo ello parece contrastar con esa orientación jurisprudencial que establece los límites del vicio de capacidad sólo en referencia con los supuestos de capacidad genérica ${ }^{63}$.

Entonces si la jurisprudencia, por un lado, reconduce al vicio de incompetencia funcional un supuesto de nulidad absoluta y si, en particular, encuentra dicho vicio en la idoneidad específica del juez de realizar un determinado acto no se comprende por qué se puede negar la existencia de una nulidad en aplicación del art. 178, párrafo 1, letra a) del código procesal penal cada vez que estamos en presencia de un vicio de capacidad específica para llevar a cabo un determinado acto. En caso contrario sería necesario llegar a la conclusión de que el defecto de incompetencia funcional está construido fuera de los casos y de los esquemas previstos por la ley. Todo ello, es sabido, no está permitido por el régimen de taxatividad que informa las nulidades procesales; así pues, es necesario constatar que la orientación jurisprudencial, reconociendo la nulidad del acto sólo en presencia de un vicio de capacidad genérica, no se basa en la interpretación del dato normativo, sino que constituye un (mal) ejemplo de política judicial.

De ahí que se deba reconducir la incompetencia funcional a un vicio típico del acto. Viéndolo bien, de hecho, dicha operación ya se ha efectuado pero sin especificar a qué tipo de nulidad se reconducía. Desde el momento en el que se afirma que la

\footnotetext{
${ }^{62}$ Vid. Casación, Sala Única, 20 de julio de 1994, De Lorenzo, cit; SABATINI, Trattato dei procedimenti incidentali nel processo penale, cit., 139, donde se afirma que «la noción de competencia funcional deriva de la distinción entre función en abstracto y función en concreto. La concretización de la función abstracta del proceso concreto en referencia con cada uno de los órganos constituye la competencia funcional de éstos últimos. Y dado que, como hemos aclarado en otros puntos, la función consiste en el ejercicio de un cierto número de poderes, la competencia funcional no es otra cosa que la legitimación del órgano para el ejercicio concreto de los poderes que le derivan directamente de su función, considerada de manera abstracta. Asimismo, puesto que la concretización de la función está determinada por la existencia de un proceso y la competencia es un presupuesto procesal, el ámbito de la competencia funcional queda determinado por la relación jurídica procesal por lo que puede llegarse a la conclusión de que la competencia funcional es la esfera de atribución para el ejercicio de los poderes derivados directamente de la función considerada en abstracto, a cada órgano judicial y que atienen a la validez de una determinada relación jurídica procesal en su constitución y desarrollo». Así pues, si la competencia funcional es un presupuesto procesal y si, en cualquier caso es lo que otorga legitimación al órgano para el ejercicio de los poderes que le derivan directamente de la función, habrá incompetencia cada vez que dichos poderes no quedan reconocidos o incluso se excluyen de las atribuciones del órgano.

${ }^{63}$ Vid. Casación, Sala III, 5 de diciembre de 2013, C., cit.; Id., Sala III, 14 de noviembre de 2003, J., cit.; Id., Sala III, 20 de febrero de 2001, Perfetti, en Cass. pen., 2002, 2443; Id., Salas Unidas, 24 de noviembre de 1999, Scrudato, cit.
} 
competencia es un «presupuesto procesal» ${ }^{64} \mathrm{y}$ en particular que la competencia funcional es un «requisito de idoneidad especifica» del juez para llevar a cabo un determinado acto o para conocer una determinada cuestión o asunto ${ }^{65}$ no cabe duda de que dichas afirmaciones llevan un a vicio de capacidad. Decir que el juez no es idóneo para llevar a cabo un acto o tratar una cuestión específica significa afirmar su incapacidad ${ }^{66}$.

No parece ser obstáculo para esta conclusión la fórmula del art. 7-bis del ordenamiento judicial $^{67}$. La misma dispone que «la violación de los criterios para la asignación de los asuntos, salvo el posible aspecto disciplinario, no da lugar en cualquier caso a la nulidad de las decisiones adoptadas». La disposición completa el diseño legislativo que encuentra su precursor en el art. 33, párrafo. 2, del código procesal penal. Pero, como hemos adelantado, no parece que pueda influir en aquellas situaciones jurídicas en las que la al juez le faltan los requisitos mínimos de jurisdicción. En efecto, éstos no tienen nada que ver con los «criterios para la asignación de $\operatorname{los}$ asuntos ${ }^{68}{ }^{6}$, sino que se refieren a la capacidad para conocer del asunto independientemente del criterio de asignación del mismo ${ }^{69}$.

\footnotetext{
${ }^{64}$ Así, Casación Sala de Guardia, 2 de septiembre de 1996, Pacifico, cit.; Id., Salas Unidas, 20 de julio de 1994, De Lorenzo, cit.

${ }^{65}$ En este sentido, vid. Casación, Salas Unidas, 23 de abril de 1974, Massazza, en Mass. Uff., n ${ }^{\circ}$ 128379; Id., Sala III, 19 de abril de 1991, Spataro, cit.

${ }^{66}$ No es casual que se haya observado que «la noción de competencia funcional deriva de la distinción entre función en abstracto y función en concreto. La concretización de la función abstracta del proceso concreto en referencia con cada uno de los órganos constituye la competencia funcional de éstos últimos. $\mathrm{Y}$ dado que, como hemos aclarado en otros puntos, la función consiste en el ejercicio de un cierto número de poderes, la competencia funcional no es otra cosa que la legitimación del órgano para el ejercicio concreto de los poderes que le derivan directamente de su función, considerada de manera abstracta. Asimismo, puesto que la concretización de la función está determinada por la existencia de un proceso y la competencia es un presupuesto procesal, el ámbito de la competencia funcional queda determinado por la relación jurídica procesal por lo que puede llegarse a la conclusión de que la competencia funcional es la esfera de atribución para el ejercicio de los poderes derivados directamente de la función considerada en abstracto, a cada órgano judicial y que atienen a la validez de una determinada relación jurídica procesal en su constitución y desarrollo». Así SABATINI, Trattato dei porcedimenti incidentali nel processo penale, cit. 139. Así pues, si la competencia funcional es un presupuesto procesal y si, en cualquier caso es lo que otorga legitimación al órgano para el ejercicio de los poderes que le derivan directamente de la función, habrá incompetencia cada vez que dichos poderes no quedan reconocidos o incluso se excluyen de las atribuciones del órgano.

${ }^{67}$ La disposición ha sido modificada por la ley n ${ }^{\circ} 111$ de 2007.

${ }^{68}$ En sentido contrario, vid. SANTORIELLO, Diritto ad un giudice idoneo, en Principi europei del processo penale, cit., 161.

${ }_{69}$ Por otro lado, la jurisprudencia también ha precisado que, frente a la asignación de los procesos violando las tablas de organización de la oficina, puede observarse una nulidad en aplicación del art. 178 letra a) del código procesal penal cuando se provoca una alteración de los principios y cánones esenciales del ordenamiento judicial, por la violación de normas como las relativas a la titularidad del poder de asignación de los asuntos que corresponde a los directivos de las oficinas y la obligación de explicar el motivo de las decisiones. Así, Casación, Sala VI, 31 de marzo de 2015, Vitale, en Mass. Uff., n 263079;
} 
Por otro lado, parece que comparte esta conclusión aquella jurisprudencia que reconoce la nulidad absoluta de la decisión tomada por un juez recusado en el supuesto de posterior estimación de la declaración de recusación; sanción procesal ésta «derivada de la comprobación de no idoneidad del juez para el correcto ejercicio de la función judicial en relación con un específico procedimiento, y por ello tiene que ver no con la atribución en abstracto de la potestad jurisdiccional, sino con las formas y límites del poder ejercitable en un determinado juicio. Una vez reconocida la imparcialidad como requisito esencial de la función jurisdiccional, dicha falta de idoneidad en concreto derivada de defecto de imparcialidad no es más que un defecto de capacidad particular para juzgar, que exigencias sistemáticas imponen reconducir a lo previsto por el art. 178 , párrafo 1 , letra a) del código procesal penal » ${ }^{70}$.

El principio, técnicamente correcto, desvela una contradicción de fondo en referencia a aquellas pronunciaciones que, por el contrario, limitan la invocación del vicio de capacidad sólo a los supuestos en los que el juez carece de los requisitos mínimos de jurisdicción. Lo que no se entiende es el motivo por el que una misma situación jurídica que encaja en el esquema legal del art. 178, letra a) del código procesal penal se considera de forma diferente según se haya llegado a una decisión de recusación o no. Sobre este punto es suficiente considerar que ésta última no constituye elemento que integra "supuesto-vicio de capacidad". Entonces, conscientes del principio de taxatividad que informa el régimen de las nulidades, dicha contradicción puede encontrar su origen sólo en momentos operativos que tienden a evitar las garantías tuteladas por las invalideces procesales.

Sin embargo, incluso queriendo considerar que el vicio de capacidad puede observarse sólo frente a una falta de los requisitos genéricos de ejercicio de las funciones jurisdiccionales, hay que destacar que este supuesto tiene lugar en los casos de defecto de tercialidad e imparcialidad del órgano jugador. La afirmación tiene su origen en la conciencia de que la orden constitucional afirma una instrumentalidad de la jurisdicción respecto al proceso justo. $Y$ dado que no puede existir jurisdicción sin un juez tercero e imparcial, dichos requisitos pasan a ser elementos presupuesto para la

Id., Sala fer., 29 de agosto de 2013, Agrama, ivi, n 256570; Id., Sala VI, 14 de julio de 2005, Colubriale, ivi, $\mathrm{n}^{\circ} 232310$; Id., Sala I, 7 de mayo de 2003, Solito, ivi, $\mathrm{n}^{\circ} 227212$.

${ }^{70}$ Así, Casación, Salas Unidas, 27 de enero de 2011, Tanzi, en Cass. pen., 2011, 4210. 
realización del proceso justo. De aquí deriva la evidente falta de requisitos genéricos de ejercicio de las funciones jurisdiccionales ${ }^{71}$.

En efecto, desde el momento en el que el Constituyente, con una disposición con alcance preceptivo, ha decidido establecer en la tercialidad e imparcialidad del juez unos "requisitos de existencia" de la jurisdicción, no cabe duda de que la falta de los mismos pone en evidencia respecto al juzgador la falta de aquellos "rasgos mínimos" para la realización de una función de juicio. La situación puede trasladarse a una auténtica "falta de poder" ${ }^{, 72}$. Por otro lado, regulando de esta manera los caracteres mínimos de la jurisdicción, el Constituyente lo que ha hecho ha sido adecuarse a las enseñanzas de la Corte Constitucional que se ha sucedido a lo largo del tiempo; en esta instancia, en efecto, además de haberse puesto en evidencia que la tercialidad era una «forma de ser de la jurisdicción» ${ }^{73}$, también se había destacado que los rasgos de tercialidad e imparcialidad existían para la tutela no sólo y no tanto del interés del individuo, sino sobre todo del interés general del ordenamiento de llegar a una decisión justa. Así se ha precisado correctamente que «los requisitos constitucionales de los jugadores, aún antes de una pretensión de la parte, constituyen exigencias objetivas e irrenunciables del ordenamiento» ${ }^{74}$. La conclusión lleva a posteriores resultados sólo si se considera el reconocimiento, explicitado por el art. 111 de la Constitución, de la jurisdicción como presupuesto del proceso ${ }^{75}$. En este sentido, como hemos visto, ya se había orientado la Corte Constitucional cuando había afirmado que «en el ámbito del principio del proceso justo, del que esta Corte, en numerosas ocasiones, ha definido los perfiles sobre la base de las disposiciones constitucionales destinadas a la regulación de la jurisdicción, ocupa un lugar central

\footnotetext{
71 Sobre el tema del establecimiento de un perfil de vicio de capacidad frente a una falta de tercialidad e imparcialidad del órgano juzgador, se permita el reenvío a DINACCI, Giurisdizione penale e giusto processo verso nuovi equilibri, cit., 54 y 321.

${ }^{72}$ Prescindiendo del hecho de que surja un perfil de inexistencia del acto, lo que aquí debe destacarse es que la jurisprudencia, relegando el vicio de capacidad sólo a los supuestos en los que faltan los requisitos genéricos de ejercicio de las funciones jurisdiccionales, realiza una interpretación que pone en evidencia momentos de confusión entre la inexistencia y la nulidad. Y ello es una prueba más de la equivocación de la línea interpretativa adoptada.

${ }^{73}$ En este sentido, Corte Constitucional, $\mathrm{n}^{\circ} 241$ de 1999.

${ }^{74}$ Así, Corte Constitucional, $\mathrm{n}^{\circ} 155$ de 1996.

75 Sobre la noción de presupuesto procesal vid. CONSO, I fatti giuridici processuali penali, cit., 170; GAITO, Procedibilità, en Enc. dir., XXXV, Milano, 1986, 806; ID., Competenza ed incompetenza e relativa declaratoria. I conflitti, en Riv. dir. proc., 1998, 378; LEONE, Trattato di diritto processuale penale, Napoli, I,1961, 157; MASSARI, Il processo penale nella nuova legislazione italiana, II, Napoli, 1934, 565; MANZINI, Trattato di diritto processuale italiano, Conso y Pisapia coordinadores, IV, Torino, 1972, 3 .
} 
la imparcialidad-neutralidad del juez, a falta de la cual, todas las demás reglas y garantías procesales perderían su significado concreto» ${ }^{76}$. Parece seguir la misma línea esa jurisprudencia que ha observado que la competencia es un «presupuesto procesal que no puede separarse de la actividad de jurisdicción» y que está dirigida a «garantizar la abstracta imparcialidad del juez a través de la preconstitución de instrumentos objetivos para establecer su esfera de cognición» ${ }^{77}$.

Así pues, es necesario tener en cuenta de que existe un reconocimiento del hecho de que ciertos valores, como la tercialidad y la imparcialidad del juez, no son disponibles según el humor y la de licencia de las partes en cuanto están implicados intereses de toda la colectividad ${ }^{78}$; en este contexto debe entenderse el significado del reconocimiento de la jurisdicción, y por sus caracteres propios, el reconocimiento del papel de presupuesto procesal ${ }^{79}$.

\section{VII.- LA INUTILIZABILIDAD}

La falta de observación de los requisitos de tercialidad e imparcialidad del juez nos pone delante de un sujeto que, aunque formalmente es juez, no posee sus caracteres identificativos. De esta manera, en la medida en la que ese sujeto se dirige a obtener elementos probatorios, es necesario comprobar si el correspondiente procedimiento adquisitivo resulta caracterizado por la violación de una prohibición legal relevante en aplicación del art. 191 del código procesal penal. Sobre este punto el carácter genérico de la fórmula léxica no deja lugar a dudas; por previsión de ley debe entenderse no sólo la expresamente contemplada, sino también la enunciada de manera indirecta: pensemos

\footnotetext{
${ }^{76}$ Vid. Corte Constitucional, n 308 de 1997.

${ }^{77}$ Vid. Casación, Sala de Guardia, 13 de agosto de 1996, Pacifico, cit.; Id., Salas Unidas, 25 de octubre de 1994, De Lorenzo, cit.; Tribunal de Perugia, 6 de diciembre de 1996, Verde, en Rass. Giur. umbra, 1997, 515.

${ }^{78}$ Así GAITO, Competenza ed incompetenza e relative declaratorie. I conflitti, cit., 379; UBERTIS,

L'incompatibilità del giudice ha pure risvolti europei, cit., 1520.

79 En el sentido por el que constituye "presupuesto procesal" la existencia de un órgano dotado de jurisdicción vid. GAITO, Procedibilità, cit,. 806; FLORIAN, Principi di diritto processuale penale, Torino, 1926, 58; LEONE, Trattato di diritto processuale penale italiano, I, cit., 157; MANZINI, Trattato di diritto processuale penale italiano, a cura di Conso e Pisapia, IV, cit., 3; MASSARI, Il processo penale nella nuova legislazione italiana, II, cit.; 565; SABATINI, Trattato dei procedimenti incidentali, cit., 249; para una noción de presupuesto procesal como elemento que se refiere a la constitución legal del proceso, GAITO, Competenza ed incompetenza e relative declaratorie. I conflitti, cit., 377.
} 
en supuesto en el que el caso está construido en términos de permisión o bien en el supuesto de que su operatividad dependa de condiciones y presupuestos ${ }^{80}$.

En dichas circunstancias nadie duda de que, si bien no existe la previsión expresa de una prohibición legal, a través de las fórmulas "está prohibido", "no puede", "no se admiten", “no están permitidas", ésta puede deducirse de la premisa legislativa que autoriza a la adquisición y, por tanto, a la valoración de la prueba sólo en presencia de aquellos requisitos que permiten la operatividad del asunto ${ }^{81}$; en efecto, éste último producirá sus efectos siempre que resulte integrado el correspondiente esquema legal. Por otro lado sería totalmente irrazonable, en el caso de que la voluntad legislativa se resuelve en una prohibición, excluir la sanción de la inutilizabilidad sólo para los modos expresivos empleados de vez en vez. Así pues, es necesario prescindir de éstas últimos pudiendo resultar las mismos incluso casuales, como parece ponerse de manifiesto en aquellas disposiciones que, tras una lista de actos consentidos, califica los residuales como no admitidos o bien admitidos con limitaciones $^{82}$. Lo aquí afirmado no puede encontrar obstáculo en la consideración según la cual el legislador se ha preocupado de prever expresamente la inutilizabilidad en algunas disposiciones $\operatorname{legales}^{83}$; en efecto, en el caso de que de dicha circunstancia quisiera deducirse la existencia de un "sistema cerrado" no se entendería por qué, además de las disposiciones especiales en las que legislador ha regulado expresamente la inutilizabilidad, se ha advertido la exigencia de una previsión que regulara de forma general la materia; y menos se comprendería el

\footnotetext{
${ }^{80}$ Sobre este punto vid. GRIFANTINI, Inutilizzabilità, en Dig. Disc., Torino, VII, 1993, 246; NOBILI, La nuova procedura penale, cit., 154; ID. Divieti probatori e sanzioni, en Giust. pen., 1991, III, 647; PIERRO, Una nuova specie di invalidità: l'inutilizzabilità degli atti processuali penali, Napoli, 1992, 145; SIRACUSANO, Le prove, in Diritto processuale penale, Milano, I, 1994, 375. Sobre este tema, si se desea, vid, L'inutilizzabilità nel processo penale. Struttura e funzione del vizio, Milano, 2008, 52. La jurisprudencia también ha reconocido que las prohibiciones probatorias deben identificarse no sólo como «las expresamente previstas por el ordenamiento procesal como sucede, por ejemplo, en los casos indicados en los art. 197 y 234, párrafo 3, del código procesal penal, o sea en materia de incompatibilidad para declarar como testigo o en relación con la imposibilidad jurídica de adquirir documentos cuyo contenido haga referencia a las voces corrientes del público, pero también pueden deducirse del ordenamiento, y eso sucede todas las veces en que las prohibiciones en tema probatorio no pueden separarse de los presupuestos normativos que condicionan la legitimidad intrínseca del procedimiento formativo o adquisitivo de la prueba». Vid. Casación, Salas Unidas, 27 de marzo de 1996, Sala, en Giust. pen., 1997, III, 139; en los mismos términos vid. también Id., Salas Unidas, 13 de julio de 1998, Gallieri, en Cass. pen., 1999, 465, 157.

${ }^{81}$ Piénsese en el supuesto previsto por los art. 266 párrafo 1 y $2 ; 103$ párrafo $1 ; 360$ párrafo 1 y $5 ; 325$ párrafo $1 ; 352$ párrafo $4 ; 355$, párrafo 2 y 3 del código procesal penal.

${ }^{82}$ Es el supuesto, por ejemplo, de los art. 238, párrafo 4, e 254, párrafo 3 del código procesal penal.

${ }^{83}$ Vid. art. 271, párrafo 1; 195 párrafo 3 y 7; 203; 63, párrafo 1 y 2; 240, 350 párrafo 6 y 7 del código procesal penal.
} 
motivo por el que una serie de disposiciones, aun previendo expresamente la prohibición, no contempla la sanción y los efectos que, por el contrario, se deducen de la disposición general del art. 191 del código procesal penal ${ }^{84}$.

Esta circunstancia es muestra del hecho de que la previsión de la norma general es una demostración de la voluntad de no limitar los supuestos de inutilizabilidad sólo a aquellos supuestos que la castigan expresamente.

En relación con lo afirmado, tampoco valdría la objeción de que las características objetivas del juez no logran integrar una prohibición legal sobre la prueba, sino sólo sobre sus modos de obtención. En efecto, si es verdad que según la opinión original de los compiladores la inutilizabilidad se había concebido sólo respecto al momento de la admisión de la prueba, mientras que «la nulidad [quedaría] reservada a la violación de las formas de los actos» ${ }^{85}$, también es verdad que dicha simetría no ha quedado confirmada en el texto definitivo donde, y no es casualidad, se prevén supuestos normativos en los que la sanción de la inutilizabilidad, o el correspondiente precepto construido como prohibición, también resultan dictados por los modos de adquisición-formación de la prueba $^{86}$. En este contexto debe apreciarse la enmienda aportada al art. 191 del código procesal penal que ha sustituido la locución original «pruebas admitidas» por la de «pruebas adquiridas». La referencia a la adquisición impone tomar en consideración esta fórmula como intencionalmente no restrictiva. Para convencerse de ello es suficiente pensar en las características del procedimiento probatorio ${ }^{87}$; éste, como es sabido, se compone de tres momentos diferentes de la progresión procesal ${ }^{88}$ constituidos por la admisión, la adquisición-formación y por último la valoración.

\footnotetext{
${ }^{84}$ Entre los muchos casos vid. los art. 62, 220, párrafo 2 del código procesal penal.

${ }^{85}$ Vid. Relazione al Progetto Preliminare al Codice di procedura penale, Roma, 1988, 61. id. Relazione al Progetto Preliminare al Codice di procedura penale, Roma, 1988, 61.

${ }^{86}$ Vid., por ejemplo, los art. 271, párrafo 1; 350, párrafo 6; 251, párrafo 1 del código procesal penal.sobre este punto vid., ya en estos términos, NOBILI, Art. 191, en Commento al nuovo codice di procedura penale, Chiavario coordinador, II, 1990, Torino, 412.

${ }^{87}$ Sobre este tema vid. CORDERO, Tre studi sulle prove penali, Milano, 1963, 53.

${ }^{88}$ Sobre las características progresivas del procedimiento vid. CONSO, I fatti giuridici processuali penali, cit., 131; SABATINI, Trattato dei procedimenti incidentali nel processo penale, Torino, $1953,11$. Éste último autor identifica la noción de conexión causal de los actos con el concepto de vínculo jurídico, afirmando que esa energía que emana el acto que establece la conexión causal con el acto siguiente del procedimiento. En el sentido de que el procedimiento es una «combinación de actos cuyos efectos están relacionadas causalmente» y que «no hay un efecto único sino un efecto final»vid. CARNELUTTI, Teoria generale del diritto, Roma, 1940, 425.
} 
Entonces, frente una regulación que prevé la prohibición de utilización de un resultado cognoscitivo, haber referido dicha prohibición también al momento adquisitivo puede significar sólo la voluntad de cubrir con la inutilizabilidad cualquier violación de todo el procedimiento probatorio. En sustancia, se ha afirmado la operatividad de la sanción incluso en un momento posterior del procedimiento probatorio; las características de éste último ${ }^{89}$ llevan en términos de tranquilidad a la conclusión de que la tutela del momento adquisitivo implica y supone la del anterior momento de admisión ${ }^{90}$. Dicha realidad ha sido acogida y subrayada también por la jurisprudencia cuando ha afirmado que por prueba entiende «tanto el medio, el instrumento, el vehículo de conocimiento de un hecho deducido en el proceso como el resultado gnoseológico ofrecido a la percepción del juez» ${ }^{91}$.

El valor polisemántico del término prueba recibe, desde el punto de vista de la regulación normativa, configuración unitaria en la reconstrucción del «acontecimiento probatorio en términos de secuencia o de sucesión de actos destinados a ofrecer el conocimiento de los hechos deducidos en la res iudicanda y a establecer la convicción del juez respecto a los mismos [...]; ha quedado consolidada la referencia a la figura del procedimiento probatorio, al análisis de las fases en las que éste se articula y al medio funcional que enlaza los diferentes momentos que, aunque son autónomos estructuralmente, están proyectados hacia la decisión final»» ${ }^{92}$.

El enunciado resulta aún más significativo si se considera que funciona como premisa de la conclusión según la cual «la inutilizabilidad prevista por el art. 191 del código procesal penal actúa en un doble de plano: como previsión de adquisición y como prohibición de uso de la prueba» precisándose que, respecto al primer aspecto, «la

89 Como todos los procedimientos, el probatorio también está caracterizado por la nota de la obligatoriedad en base a la cual la relación entre los actos tiene implicación en el sentido de que el anterior obliga a la realización del acto siguiente. Sobre este punto vid. CONSO, I fatti giuridici processuali penali, cit., 134.

90 Sobre el concepto de adquisición vid. CHIAVARIO, La riforma del processo penale, Appunti sul nuovo codice, Torino, 1990, 128; COMOGLIO, Prove ed accertamento dei fatti nel nuovo c.p.p., en Riv. it. dir. proc. pen., 1990, 126.

91 Así, Casación, Salas Unidas, 25 de febrero de 1998, Gerina, en Cass. pen., 1998, 1951, 1115; Id., Salas Unidas, 13 de julio de 1998, Citaristi, en Giust. pen., 1999, III, 355. Sobre este tema vid. también Casación, Salas Unidas, 28 de mayo de 2003, Torcasio, en Mass. Uff., n. 225467 que ha subrayado que la disposición prevista en el art. 191 del código procesal penal se refiere a una «prohibición de adquisición»; habla de «prohibición de admisión» Casación, Sala V, 18 de julio de 2014, V.G., en Mass. Uff., nº 260073.

92 Vid., Casación, Salas Unidas, 25 de febrero de 1998, Gerina, cit. 
inutilizabilidad impide la admisión y la asunción del medio de prueba afectado por la prohibición» ${ }^{93}$.

Por lo tanto, parece fuera de discusión que haber modificado el art. 191 del código procesal penal sustituyendo el término «admisión» por «adquisición», expresa la voluntad de tutelar con una norma de garantía la regularidad de todo el procedimiento probatorio ${ }^{94}$. Y cuando ésta queda tocada por la falta de los caracteres en los que se basa el presupuesto constitucional de la jurisdicción, la "prohibición de uso" también se obtiene desde la perspectiva de la llamada prueba inconstitucional ${ }^{95}$; esta circunstancia que también logra superar la querelle que tiende a valorar si el campo de acción de la inutilizabilidad se refiere sólo a la prueba ex se o también al quomodo de la misma. Sin embargo, la invocación de la inutilizabilidad no podría prestarse a resolver, en cualquier situación, el déficit de los requisitos jurisdiccionales a causa, por un lado, de las resistencias que actúan para de reconocer al vicio de inutilizabilidad una capacidad de propagación $^{96}$, y, por otro lado, en la presencia de aquellos ritos en los que el juez no procede a adquisiciones probatorias, limitándose a una función de juicio de simple valoración ${ }^{97}$.

\footnotetext{
${ }^{93}$ Vid., Casación, Salas Unidas, 25 de febrero de 1998, Gerina, cit.

${ }^{94}$ Sobre este tema, para profundizar, vid, si se desea DINACCI, L'inutilizzabilità nel processo penale. Struttura e funzione del vizio, cit., 56.

${ }^{95}$ En efecto, en este supuesto estaríamos en presencia de «actuación realizada despreciando los derechos fundamentales del ciudadano»y, por ello, según la enseñanza de la Corte Constitucional, los correspondientes resultados «no pueden asumirse, por sí mismos, como justificación y fundamento de quienes hayan sufrido dichas actuaciones constitucionalmente ilegítimas». Así, Corte Constitucional sentencia ${ }^{\circ} 34$ de 1973; Id., n 81 de 1993; Id., n 229 de 1998. Para un expreso reconocimiento de la inutilizabilidad por prueba inconstitucional, vid. Casación, Salas Unidas, 23 de febrero 122000 , D'Amuri, en Cass. pen., 2000, 2595, 1419; en los mismos términos Id., Salas Unidas, 21 de junio de 2000, Tammaro, ivi, 2000, 3259, 1763; Id. Salas Unidas, 24 de septiembre de 1998, Gallieri, cit.; Id. Salas Unidas, 25 de febrero de 1998, Gerina, cit., Id., Salas Unidas, 27 de marzo de 1996, Sala, cit.

${ }^{96}$ Vid. Casación, Sala I, 29 de septiembre de 2015, El G., en Cass. pen., 2016, 2577; Id., Sala V, 20 de noviembre de 2014, S., ivi, 2015, 4101; Id., Sala V, 11 de noviembre de 2011, $\mathrm{n}^{\circ} 21047$, en Mass. Uff., $\mathrm{n}^{\circ}$ 250415. Sobre este tema, para una mayor profundización, permitan la remisión a DINACCI, L'inutilizzabilità nel processo penale. Struttura e funzione del vizio, cit., 91.

${ }^{97}$ Piénsese en los procedimientos camerales, en el proceso ante la Corte de Casación y juicio de apelación mismo, si no se procede a la renovación de la declaración de prueba.
} 


\section{VIII.- LA INEXISTENCIA}

El cuadro constitucional de los requisitos de imparcialidad y tercialidad del juez entre los presupuestos procesales ${ }^{98}$ lleva a pensar en términos de inexistencia del acto y dicha hipótesis reconstructiva resulta legitimada por la línea de la jurisprudencia que no reconoce, frente a situaciones en las que se produce una falta de tercialidad e imparcialidad del órgano juzgador el vicio de capacidad del juez. El tema se plantea también en el supuesto en el que no se observara la incidencia de la prohibición de uso prevista por el art. 191 del código procesal penal, o bien en los límites de la operatividad parcial del mismo debida a las características del rito ${ }^{99}$.

No se puede objetar la ambigüedad del recurso a la categoría de inexistencia pues no está directamente contemplada por el legislador. No cabe duda de que la inexistencia, como figura "falsificada" de invalidez, se delinea a través de elementos convencionales ${ }^{100}$. En efecto, dando por descontada una especie de «crisis de hipertrofia del concepto» ${ }^{101}$, la idea de que el acto inexistente puede sólo «aproximadamente delinearse, no definirse sino exactamente intuirse» ${ }^{102}$, traiciona el carácter parcialmente empírico del correspondiente análisis gnoseológico ${ }^{103}$.

Sin embargo, no obstante los numerosos «intentos ortopédicos de la exégesis» ${ }^{104}$, se ha logrado identificar la colocación operativa de la inexistencia como «falta de la mínima identificación necesaria del acto» ${ }^{105}$, o bien como falta de los requisitos esenciales para la identificación del mismo ${ }^{106}$. Y en realidad, considerando que cada acto está compuesto por «elementos de estructura cuya suma es necesaria y suficiente para que pueda decirse que el paradigma al que alude el legislador está integrado» ${ }^{107}$, la falta de uno de estos elementos impide «cualquier asimilación entre

\footnotetext{
${ }^{98}$ Se ha afirmado correctamente que «la expresión presupuesto procesal entendido al pie de la letra lleva a pensar en las circunstancias sensatas sin cuales no existiría el proceso o la relación procesal» $\mathrm{CONSO}, I$ fatti giuridici processuali penali, cit., 170.

${ }^{99}$ Vid. infra $\S 8$.

${ }^{100}$ Vid. CORDERO , L'“inesistenza” della decisione giudiziaria, cit., 606.

101 Vid. CORDERO, L'“inesistenza”' della decisione giudiziaria, cit., 602, nota 1.

${ }^{102}$ Así DE MARSICO, Diritto processuale penale, cit., 143.

${ }^{103}$ Correctamente en este sentido MAMBRUCCHI, Le forme di documentazione dell'attività del pubblico ministero, in Studi sul processo penale, coordinador Gaito, Padova, 1996, 241.

${ }^{104}$ Vid. PANNAIN, Le sanzioni degli atti processuali penali, cit., 240.

105 Vid. TORRENTE, Spunti per uno studio sull'inesistenza e sulla nullità della sentenza, in Studi in onore di Redenti, II, Milano, 1951, 395.

${ }^{106}$ Así MASSARI, Il processo penale nella nuova legislazione italiana, II, cit., 456.

${ }^{107}$ En este sentido CORDERO, L'inesistenza della decisione giudiziaria, cit., 611.
} 
lo que ha sido, y que tiene la apariencia del acto, y el acto tipificado por la norma» ${ }^{108}$. En estos casos la total improductividad de cualquier efecto jurídico pone en evidencia la «vistosidad de la imperfección» ${ }^{109}$ que, además de impedir la producción de los efectos del acto imperfecto, tampoco permite su producción de forma precaria ${ }^{110}$.

Así pues, el problema se traslada a la identificación de los requisitos que constituyen el «coeficiente genético» del acto ${ }^{111}$. La operación pone en evidencia dificultades a causa de la falta de una específica referencia normativa. Pero la consideración no libra al intérprete de un esfuerzo reconstructivo considerando la función de garantía que juega la figura de la inexistencia. Ésta última tiene su origen en la necesidad de no dejar "descubiertos" aquellos vicios del acto que no entran entre las acciones reguladas expresamente; en particular se hace referencia a aquellos supuestos tan radicales que el legislador ni siquiera ha pensado prever; si es así, no cabe duda de que el ámbito de operatividad de la inexistencia debe encontrar un parámetro de límite en la regulación de la nulidad y de la inutilizabilidad ${ }^{112}$. Por otro lado, anclar los espacios operativos de la inexistencia a vacíos dejados por dicha regulación plantea un doble límite que resulta útil para encuadrar a la categoría: en efecto, por un lado no es diagnosticable como causa de inexistencia la dificultad entre el acto y el relativo esquema legal cuando la misma es menor que las asumidas por la ley como causas de nulidad y de inutilizabilidad; por otro lado, no puede observarse un supuesto de acto inexistente cuando el vicio ya está encuadrado como causa de invalidez. Y ello por el simple motivo de que la inexistencia se diferencia de los vicios expresamente regulados y, por lo tanto, la misma no puede plantearse en lo que la ley regula como existente aunque viciado.

La jurisprudencia también ha seguido esta conclusión poniendo en evidencia que el recurso a la existencia «que comprende esos vicios tan macroscópicos como para inducir a legislador a no plantear ni siquiera su eventualidad y al intérprete a negar su

\footnotetext{
${ }^{108}$ Vid. PETRELLA, Le impugnazioni nel processo penale, I, Milano, 1965, 77.

${ }^{109}$ Sobre este punto véanse los argumentos de MAMBRUCCHI, La forma di documentazione dell'attività del pubblico ministero, cit., 242.

${ }^{110}$ Vid. CONSO, Il concetto e le specie d'invalidità, cit., 98.

111 La terminología es de MAMBRUCCHI, La forma di documentazione dell'attività del pubblico ministero, cit., 242.

${ }^{112}$ En el sentido de que una investigación similar debe llevarse a cabo con método deductivo, es decir, a través del análisis del sistema de los principios que informan cada figura procesal vid. MAMBRUCCHI, La forma di documentazione dell'attività del pubblico ministero, cit., 242, sobre este punto véase también CORDERO, L'inesistenza della decisione giudiziaria, cit., 611; GAITO, Il giudizio direttissimo, Milano, 1980,340 .
} 
colocación en el marco de los actos jurídicos, sigue planteándose como el resultado de una operación interpretativa; así ésta no puede diagnosticarse nunca cuando el vicio ya recae en una especie de invalidez regulada por la ley» ${ }^{113}$.

Por lo tanto, el ámbito aplicativo de la categoría de la existencia del acto se recorta negativamente de lo que expresamente está regulado por el ordenamiento considerando los supuestos de invalidez y ello a causa de la diversidad ontológica que se observa entre un acto que no existe y otro que, aunque esté viciado, no sólo existe sino que en determinadas ocasiones puede producir sus efectos. Es suficiente pensar en los supuestos de subsanación. Desde esta perspectiva la inexistencia del acto debe reconducirse a aquella «zona de irregularidad que queda fuera del ámbito de eficacia de la subsanación ${ }^{114}$. De aquí también deriva el sentido de reconducir el acto inexistente a los supuestos de falta de los presupuestos procesales y, entre éstos, el primero de todos es el referente a la jurisdicción ${ }^{115}$.

No es casual que la jurisprudencia también haya reconocido la inexistencia jurídica de una decisión en el supuesto en el que la misma carezca «de los requisitos mínimos como la procedencia de un órgano titular del poder jurisdiccional»» ${ }^{116}$; en particular, se ha precisado que también se da un supuesto de inexistencia del acto cuando un «sujeto investido de potestad jurisdiccional se asume un poder que no se le atribuye a él personalmente sino al órgano colegiado del que forma parte» ${ }^{117}$.

\footnotetext{
${ }^{113}$ Vid. Corte de Casación, Salas Unidas, 17 de abril de 1996, Pagnozzi, en Cass. pen., 1996, 3286, 1813; Id., Corte de Casación, Sala VI, 4 de enero de 2000, Rizzo, ivi, 2001, 1296.

${ }^{114}$ Así LEONE, Trattato di diritto processuale penale, I, cit. 743.

${ }^{115}$ Sobre este tema vid. LEONE, Trattato di diritto processuale penale, I, cit. 238.

${ }^{116}$ Vid. Casación, Sala I, 19 de marzo de 1996, Jordanovic, en Cass. pen., 1997, 14221; Id., Salas Unidas, 26 de abril de 1989, Goria, en Giust. pen., 1989, III, 740.

${ }^{117}$ Así, Casación, Sala. I, 15 de abril de 1983, Zoroddu, en Cass. pen., 1984, 1200, 865. El caso concreto sometido al juicio de la Corte se refería al caso de un presidente del Tribunal de lo Penal italiano que, en la fase previa del juicio, había decidido en base a una instancia la liberación por cumplimiento de los plazos de custodia cautelar.
} 
Ahora bien, independientemente de la variedad de los $\operatorname{casos}^{118}$, no parece que puede ponerse en duda la eventualidad de que cualquier forma de vicio que tiene que ver con el poder de ejercicio de las funciones jurisdiccionales no puede resolverse por el ordenamiento en un hecho neutro.

Así pues, es necesario, lo repetimos, tomar conciencia de que el tema se refiere a valores que no pueden considerarse tutelados adecuadamente según los humores y/o la diligencia de las partes ${ }^{119}$ : las fuentes supranacionales son las que imponen la observación de la orden jurídica de garantizar un juez tercero e imparcial poniendo en discusión la existencia misma de un magistrado que carezca de dichos rasgos.

Sobre este aspecto la obstinación de la jurisprudencia de excluir, en referencia a la violación de los caracteres constitucionales de la jurisdicción, cualquier forma de invalidez procesal, dirige la solución interpretativa hacia la figura de la inexistencia del acto.

\section{VIII.- CONCLUSIONES}

En conclusión, tercialidad e imparcialidad de la jurisdicción, impuestas por las "fuentes prevalentes" representadas por la Constitución, por el TEDH y por la Carta de los derechos fundamentales de la Unión Europea aunque reguladas, desde un punto de vista abstracto, a través de las instituciones de la incompatibilidad, de la abstención y de

\footnotetext{
${ }^{118}$ La jurisprudencia ha subrayado que el defecto de poder jurisdiccional determina la inexistencia del acto realizado por el sujeto que carece de dicho requisito. En particular, se ha considerado inexistente una sentencia sin la firma del juez ponente, debiéndose entender la sentencia «como acto documental de la decisión», que incluye tanto la parte dispositiva como como su «correspondiente motivación», Casación Sala II, 17 de octubre de 2000, ministerio fiscal en el juicio, Pavani, en Mass. Uff. n ${ }^{\circ} 2178888$. Y también en referencia a la decisión de archivo dictada por el Colegio especial previsto por el art. 7 de la ley de 16 de enero de $1989 \mathrm{n}^{\circ} 1$ (respecto a cuya constitución ya se habían denunciado algunos vicios) se ha afirmado que dicha medida no puede considerarse inexistente, sino nula, sobre la base de que « decisiones inexistentes son aquéllas respecto a las cuales debe excluirse su procedencia de un órgano investido de poder jurisdiccional», Casación, Salas Unidas, 26 de abril de 1989, Goria, cit. 741. Asimismo (estando vigente el código abrogado) se ha considerado inexistente la sentencia del juez Honorio diferente del juez ante el que se había desarrollado la vista de discusión (Casación, Sala I civil, 3 de abril de 1985, Bucci c Leli, en Foro it., 1986, I, 519). Por último, se ha considerado inexistente la medida dictada por el Presidente del Tribunal de lo Penal - tras una instancia de liberación por transcurso de los plazos máximos de custodia cautelar - en la fase de diligencias previas al juicio ((Casación, Sala I, 15 de abril de 1983, cit.) dado que dicha medida no era competencia de un órgano unipersonal sino colegiado. También se ha observado la inexistencia del acto de transmisión del proceso realizada por el Presidente del Tribunal de Caltanissetta (con consiguiente nulidad de todas las actuaciones posteriores) en el caso en el que se haya instituido por ley un Tribunal (en el caso de Gela) y no se haya comprobado la incompetencia territorial por sentencia. (vid. Tribunal de Gela, 12 de abril de 1991, en Gius. pen., 1991 III, 554).

119 Así exactamente GAITO, Competenza ed incompetenza e relative declaratorie. I conflitti., cit. 379.Vid.
} 
la recusación, producen un resultado concreto inadecuado a causa de una praxis aplicativa que rechaza la operatividad de sanciones procesales de garantía frente a la actuación de un juez que, encontrándose en situaciones incompatibilidad, abstención y/o recusación, sigue ejerciendo su magisterio. Ya hemos visto que dicho «instinto de conservación» que caracteriza la «concretización» de las figuras jurídicas previstas para garantizar la tercialidad y la imparcialidad del juez ya no está justificado frente a la previsión de la revisión procesal ${ }^{120}$.

En realidad, no parece controvertible que una "condición" del proceso, como es que el juez sea tercero e imparcial, si no se observa, supone una violación del proceso justo.

Por lo tanto, la obstinación de la jurisprudencia de no reconocer una vigencia concreta a las sanciones procesales conlleva el peligro de que se quede en nada ese resultado que se pretende salvaguardar, a través de la evasión interpretativa de la correspondiente regulación del código. Así pues, debe quedar clara la falta de actualidad de la dicotomía "eficiencia-garantía" y llegar a exégesis de la orden positiva en observación de las obligaciones constitucionales y comunitarias. Dichas "fuentes prevalentes", imponiendo un juez tercero e imparcial, no pueden tolerar lecturas "cómodas" que se atrincheran detrás de la barrera de las figuras jurídicas de naturaleza preventiva como la abstención y la recusación. Es necesario que el ordenamiento también logre dar una respuesta en los supuestos en los que un juez ejerce sus funciones esquivando la red de dichas figuras jurídicas; y la situación no es para nada infrecuente si se consideran sólo las complejas cargas formales y cronológicas que la parte está obligada a observar para presentar la recusación. Como si ello no fuera suficiente, el problema queda acentuado por una previsión más limitada de los casos de recusación respecto a los contemplados para la abstención. La circunstancia delinea posteriores problemas operativos. Si se recurriera a dichas figuras jurídicas carecerían de tutela los casos en los que el juez quede afectado por la llamada "fuerza de la prevención" en situaciones no contempladas. En dichos supuestos ya sean el TEDH como la Consulta ${ }^{121}$ han reconocido la necesidad de una tutela ${ }^{122}$ que, evidentemente, puede ofrecerse sólo

\footnotetext{
${ }^{120}$ Corte Constitucional, $\mathrm{n}^{\circ} 113$ de 2011.

${ }^{121}$ Vid Corte Constitucional, $n^{\circ} 86$ de 2013; $n^{\circ} 241$ de 1999; $n^{\circ} 290$ de 1998, $n^{\circ} 31$ y n 346 de $1997 ; n^{\circ}$ $131, \mathrm{n}^{\circ} 155 \mathrm{y} \mathrm{n}^{\circ} 371$ de 1996; n 432 de 1995; n 453 y n $^{\circ} 455$ de $1994 ; \mathrm{n}^{\circ} 439$ de $1993 ; \mathrm{n}^{\circ} 124, \mathrm{n}^{\circ} 186 \mathrm{y}$ n 399 de 1992; n 401 y n 502 de 1991; n 496 de 1990. Vid., también, TEDH, Fay c. Austria, cit; Id., Sainte Marie c. Francia, cit.; Id., Nortier c. Olanda, cit.
} 
mediante el recurso a las invalideces procesales. Por lo tanto, la indicada "falta alineación" entre los casos de abstención y los de recusación pone en evidencia la predilección legislativa de "confiar" a un sujeto bajo sospecha la valoración de su propia neutralidad. Pero el tema no puede quedar tutelado por instrumentos deontológicos. Y tampoco resulta satisfactoria la decisión de confiar a la iniciativa de las partes, y ello con plazos muy limitados y aún más inadecuados por las formas de aplicación de la declaración de recusación particularmente complejas, la tutela de un "presupuesto procesal".

Así pues, es necesario romper las barreras y tomar conciencia de que el tema se refiere al "conjunto" del proceso y no puede confiarse a la diligencia de las partes, ni puede sufrir los plazos angostos de apreciación de la situación jurídica patológica.

Sólo de esta manera podrá cumplirse el deber constitucional y comunitario de garantizar un proceso ante un juez tercero e imparcial.

Y quizás ésta es la clave de lectura que permite pasar de la enunciación abstracta del proceso justo a la celebración efectiva de un proceso justo; es decir, de la teoría a la práctica. 